\title{
ESCOLA E CLASSE SOCIAL DE UMA PERSPECTIVA GRAMSCIANA: A SALA DE AULA, O INTELECTUAL E OS SIMPLES
}

\author{
SCHOOL AND SOCIAL CLASSES FROM A GRAMSCIAN PERSPECTVE: \\ THE CLASSROOM, THE INTELLECTUALS AND THE SIMPLE PEOPLE
}

\author{
ESCUELA Y CLASE SOCIAL UNA PERSPECTIVA GRAMSCIANA: \\ UN AULA, EL INTELECTUAL Y LA SIMPLE
}

Renê José Trentin Silveira ${ }^{1}$

\begin{abstract}
RESUMO: O presente artigo é resultado parcial de pesquisa de pós-doutoramento desenvolvida em 2011-2012 com a Università degli Studi di Torino, sob a supervisão do Prof. Dr. Angelo D’Orsi, com apoio da Fapesp. Seu principal objetivo é discutir, a partir de Gramsci, o papel da escola na superação da sociedade de classes, situando esse autor no contexto das teorias pedagógicas que investigam essa temática. Para tanto, são examinados inicialmente dois textos gramscianos pré-carcerários de 1919 que tratam especificamente do tema da escola: um artigo publicado no Avanti!, jornal do Partido Socialista, intitulado "A escola é uma instituição séria?", e uma crônica sem título no L'Ordine Nuovo. Em seguida, busca-se articular as considerações decorrentes desse exame com conceitos e posições do autor, expressas nos Cadernos do Cárcere, enfatizando-se as noções de "estrutura" e "superestrutura", "Estado integral", "sociedade civil", "sociedade política", "racional", "guerra de movimento" e "guerra de posição". Finalmente, conclui-se que, para Gramsci, como elemento da sociedade civil, a escola é, de fato, aparelho de hegemonia da classe dominante, mas também, contraditoriamente, terreno de luta contrahegemônica, travada na forma de "guerra de posição" pelos intelectuais que nela têm seu campo específico de atuação: os professores. Além disso, pelas características que reúne, constitui espaço privilegiado para o contato entre os intelectuais e os "simples" e, portanto, um importante instrumento de elevação cultural de massa, do qual não devem abdicar os intelectuais comprometidos com as camadas subalternas.
\end{abstract}

PALAVRAS-CHAVE: Antonio Gramsci. Escola unitária. Guerra de posição. Sociedade civil. Hegemonia.

ABSTRACT: The present article is a partial result of the post-doctoral study developed in 2011-2012, as a visiting fellow at the Università degli Studi di Torino, under the supervision of Professor Angelo D'Orsi and supported by FAPESP. It aims to discuss, from a gramscian perspective, the role of the school in overcoming the society of classes, situating this author in the context of pedagogical theories that investigate this theme. Firstly, two preincarceration gramscian texts from 1919, which deal specifically with the school theme, are analysed: an article published in Avanti!, titled "Is the school a serious institution?", and an untitled chronicle published in the L'Ordine Nuovo. Next, considerations derived from this analysis are articulated with some concepts and positions from the author, expressed in the Prison Notebooks, such as "base and superstructure", "integral Estate", "political society", "civil society", "rational", "war of movement" and "war of position". Finally, it is concluded that, for Gramsci, as an element of the civil society, the school is, in fact, a tool of the hegemony of the dominant class, but also, contradictorily, the field for the counter-hegemonic fight, combated as a "war of position" by the intellectuals that have in it their specific acting domain: the teachers. Furthermore, by its characteristics, it constitutes a privileged space for the contact between the intellectuals and the "simple people" and, therefore, an

\footnotetext{
${ }^{1}$ Livre-Docente pela Universidade Estadual de Campinas na área de Filosofia da Educação. Professor do Departamento de Filosofia e História da Educação da Faculdade de Educação, Universidade Estadual de Campinas. Membro do PAIDÉIA - Grupo de Estudos e Pesquisas em Filosofia e Educação pela mesma universidade. E-mail: rene@unicamp.br.
}

Recebido em: 14/07/2015 - Aprovado em: 21/10/2015. 
important tool for the cultural elevation of the masses, from which the intellectuals committed to the subaltern classes should not abdicate.

KEYWORDS: Antonio Gramsci. Unitarian school. War of position. Civil society. Hegemony.

\section{INTRODUÇÃO}

Que papel cumpre a escola na sociedade de classes? A pergunta não é nova e a resposta varia ao sabor das posições teóricas e políticas dos que se dedicaram a buscá-la. Sem querer repisar o problema das classificações e periodizações na área da educação, e tomando como referência a Época Moderna e o advento do capitalismo, que é quando surge a escola pública, estatal, laica e universal, as teorias pedagógicas que se debruçaram sobre a questão acima enunciada podem, grosso modo, ser agrupadas em dois grandes campos teórico-políticos: $1^{\circ}$ ) o daquelas que, posicionando-se acriticamente em relação ao capitalismo, subordinam a educação escolar ao atendimento das necessidades desse modo de produção; $2^{\circ}$.) o das que, posicionando-se de modo inverso, denunciam o caráter classista da escola e sua subordinação aos interesses da classe dominante. ${ }^{i}$

As teorias do primeiro campo, em geral, inserem-se naquela que se poderia denominar de concepção liberal da relação entre educação e sociedade, segundo a qual o principal papel da escola é promover, no plano formal, a "equalização" social. A passagem abaixo, extraída de um relatório de Horacce Mann, político e educador liberal estadunidense do século XIX, endereçado ao Conselho de Educação de Boston, em 1848, parece sintetizar muito claramente essa concepção:

\footnotetext{
Ora, com toda certeza, somente a educação universal será capaz de contrabalançar a tendência ao domínio do capital e servilismo trabalho. Se uma classe possui toda a riqueza e a educação, enquanto o resto da sociedade permanece ignorante e pobre, não importa que nome se dê à relação entre eles: a última, de fato e na verdade, será constituída de dependentes servis e súditos da primeira. Mas se a educação for distribuída equitativamente, arrastará consigo a propriedade, mediante a mais forte atração; porquanto até hoje ainda não se viu que um grupo qualquer de homens inteligentes e práticos ficasse permanentemente pobre. (...) A educação, portanto, mais do que qualquer outra instituição de origem humana, constitui-se no grande nivelador das condições dos homens - o volante da máquina social. (...) Faz mais do que desarmar o pobre da hostilidade contra os ricos. Impede sejam pobres. (MANN, 1963, p. 106-107). ${ }^{\text {ii }}$
}

As formas pelas quais a escola supostamente cumpre essa tarefa de impedir os pobres de ser pobres variam de acordo com as necessidades do capitalismo em cada fase de seu desenvolvimento histórico, em resposta às quais edificam-se diferentes teorias pedagógicas, tais como: a pedagogia tradicional, a pedagogia da Escola Nova, a pedagogia tecnicista, a pedagogia não diretiva, a pedagogia das competências, entre outras. Qualquer que seja a teoria, porém, o pano de fundo é sempre o mesmo: a crença no poder da educação de agir sobre a sociedade visando a aperfeiçoá-la, sem que seja necessário transformá-la radicalmente. Trata-se, portanto, de uma posição idealista ou "não crítica", na terminologia de Saviani $(2009$, p. 5), na \begin{tabular}{l|l|l|l|l|l|l} 
(C) ETD - Educ. Temat. Digit. & Campinas, SP & v.17 & n.3 & p. 558-575 & set./dez.2015 & ISSN 1676-2592
\end{tabular} 
medida em que tais teorias desconsideram os condicionantes materiais da educação e da escola, isto é, o fato de serem, em última instância, determinadas pela estrutura econômica e social que as engendra.

As teorias do segundo campo podem ser divididas em dois subgrupos: o primeiro é o daquelas que, denunciando o caráter classista da escola, enxergam-na predominantemente (quando não exclusivamente) como instrumento de reprodução do capitalismo e, por conseguinte, da desigualdade entre as classes ${ }^{\mathrm{iii}}$. Parte dessas teorias apoia-se em uma leitura mecanicista - ou, pelo menos, pouco dialética - do marxismo, particularmente da teoria da estrutura e da superestrutura, segundo a qual esta seria determinada de forma absoluta e unilateral por aquela. Assim, a escola, sendo um elemento da superestrutura, funcionaria sempre em harmonia com a estrutura econômica e social que a condiciona, não se constituindo, portanto, como um campo propício para a luta revolucionária. Essa forma de pensar tende a enfraquecer, pela descrença em sua eficácia, a luta política no interior dessa instituição, podendo gerar certo imobilismo nos educadores progressistas, que preferirão canalizar suas energias para outros campos de atuação mais diretamente vinculadas aos interesses da classe trabalhadora, como sindicatos, movimentos sociais e partidos.

O segundo subgrupo reúne teorias que, guiando-se por uma leitura dialética do marxismo, reconhecem o caráter reprodutivista da escola, sem, porém, deixarem de admitir também a possibilidade de que, pela luta de classes que repercute no seu interior, a educação possa adquirir simultaneamente um sentido crítico, revolucionário.

Antonio Gramsci, como pensador e militante marxista, e que também tem uma importante contribuição para a reflexão e a prática pedagógicas, obviamente alinha-se aos críticos do capitalismo, inclusive no que se refere à denúncia do caráter classista da escola, por ele praticada já nos anos de sua juventude e militância jornalística, como bem o demonstrou Manacorda (2008). Mas em qual dos subgrupos acima mencionados seu pensamento pedagógico poderia ser classificado?

Pode-se responder imediatamente: no segundo subgrupo, pois, do ponto de vista de sua filosofia da práxis, que é uma filosofia materialista, mas também dialética, a determinação da superestrutura pela estrutura não é absoluta, mecânica, unilateral, mas contraditória e recíproca. Aliás, Gramsci não cansou de combater a leitura mecanicista do marxismo, como se verifica em diversas passagens de sua obra. Ora, sendo a escola elemento da superestrutura, é de se esperar que também a relação escola-sociedade seja concebida dialeticamente. Mas o que isso significa, exatamente, de uma perspectiva gramsciana? Se a escola não é mera reprodução, de que forma específica pode contribuir para a superação da sociedade de classes?

Esse é o problema central que o presente trabalho pretende enfrentar e discutir. Para tanto, serão examinados inicialmente dois textos gramscianos pré-carcerários de 1919 que abordam especificamente o tema da escola, procurando, em um segundo momento, articulá-los com algumas posições do autor expressas nos Cadernos do Cárcere. 


\section{DOIS TEXTOS PRÉ-CARCERÁRIOS}

Em uma crônica do L'Ordine Nuovo ${ }^{i v}$, na edição de agosto de $1919^{v}$, Gramsci anuncia o início da publicação de um breve estudo de Aldo Oberdorfer di Trieste sobre Leonardo da Vinci, escrito por ocasião do quarto centenário vinciano, que caía naquele ano. Justifica essa publicação esclarecendo que, como já havia sido mencionado em outras oportunidades, uma revista comunista de cultura deve tender a se transformar em uma "coisa completa", de modo que "em suas páginas todos encontrem aquilo que lhes interessa e lhes apaixona, e aquilo que os alivia do peso cotidiano do trabalho, da luta econômica, da discussão política" (GRAMSCI, 1955, p. 119). Na visão de Gramsci e de seus colegas do L'Ordine Nuovo, a revista deveria, pelo menos, incitar "a um desenvolvimento completo das próprias faculdades mentais, a uma vida mais alta e plena, mais rica de motivos ideais e de harmonia, ao estímulo a um enriquecimento da própria personalidade" (ibidem). Ao final do parágrafo, pergunta-se: "Por que não podemos nós começar, com nossa modesta força, no meio daquele grupo de jovens que nos seguem com confiança e com expectativa, a obra que será da escola, da nossa escola de amanhã?" (ibidem).

Esse "desenvolvimento completo" da classe trabalhadora, reclamado por Gramsci, ao que parece não poderia ser obra da escola de então, mas apenas daquela de amanhã, a escola socialista. Enquanto isso, a obra pode e deve ser iniciada, mas por outros meios, fora da escola. Diz Gramsci (ibidem):

\footnotetext{
Porque a escola socialista, quando surgir, surgirá necessariamente como uma escola completa, tenderá a abraçar imediatamente todos os ramos do humano saber. Será uma necessidade prática e será uma exigência ideal. Não são já agora alguns operários, aos quais a luta de classe deu um senso novo de dignidade e de liberdade que, quando leem os cantos dos poetas e ouvem os nomes dos artistas e dos pensadores, se perguntam com pesar: 'Por que a escola não ensinou essas coisas também a nós?' Mas eles se consolam: a escola, como tem sido feita nos últimos dez anos, como é feita agora pela classe que nos dirige, não ensina mais nada a ninguém, ou bem pouco. A tarefa educativa tende agora a realizar-se por outras vias, livremente, através de espontâneas associações de homens animados do desejo comum de melhorarem-se a si mesmos. Por que um jornal não poderia se tornar o centro de um desses grupos? Também neste campo o Estado dos burgueses está para falir. Por suas mãos enrugadas no esforço único de acumular riquezas para os particulares, a tocha da ciência caiu, como caiu a lâmpada sagrada da vida. A nós o levantá-la do chão, a nós o fazê-la brilhar com uma nova luz. (Grifos meus).
}

Há, sem dúvida, nessas palavras uma crítica à escola. Mas qual é o alvo exato dessa crítica? Note-se que Gramsci não se refere à escola como veículo da ideologia burguesa, como "aparelho privado de hegemonia" a serviço dessa classe, nem como instância da superestrutura cuja função seria meramente a de reproduzir a estrutura social. Sua crítica se dirige ao fato de a escola não ensinar, também aos operários, aquilo que apenas as elites aprendiam: os cantos dos poetas, os nomes dos artistas e dos pensadores, a ciência, enfim, a cultura humanística, "desinteressada", elaborada, necessária aos que anseiam por um "senso novo de dignidade e de liberdade". Pelo fato de a escola ter abandonado essa sua tarefa educativa, essa cultura torna\begin{tabular}{|l|l|l|l|l|l|l} 
(C) ETD - Educ. Temat. Digit. & Campinas, SP & v.17 & n.3 & p. 558-575 & set./dez.2015 & ISSN 1676-2592
\end{tabular} 
se privilégio de poucos. É isso o que lamentam os operários que já adquiriram esse novo senso de dignidade e liberdade.

Gramsci, porém, parece não ter grandes esperanças em relação a essa escola dos últimos anos. Já que ela está sob o controle da classe dirigente, isto é, justamente aquela classe que foi responsável por deixar cair por terra a tocha da ciência, não se pode esperar que propicie a formação cultural dos trabalhadores em conformidade com seus interesses de classe. A rigor, isso só será possível com a escola socialista que, quando vier, surgirá, esta sim, como uma "escola completa", capaz de "abraçar imediatamente todos os ramos do humano saber". Até lá, cabe a "nós", ou seja, à classe trabalhadora e aos intelectuais com ela comprometidos, reerguer a tocha da ciência e "fazê-la brilhar com uma nova luz". Para tanto, é preciso buscar "outras vias" para essa formação cultural, por exemplo, por meio de "espontâneas associações" (ibidem), livres da interferência do Estado e formadas por "homens animados do desejo comum de melhorarem-se a si mesmos" (ibidem). Essa seria, portanto, uma das principais tarefas do L'Ordine Nuovo.

Há, pois, em Gramsci uma forte desconfiança da escola burguesa, mas não tanto em relação à cultura, ao saber que ela deveria ensinar. Afinal, ele próprio reconhece que no saber historicamente acumulado pela humanidade em "um milenário trabalho de pensamento" há também elementos culturais de "valor eterno, que não podem, que não devem perecer" (p. 119120). E esses elementos, em certa medida, paradoxalmente, interessam também aos trabalhadores.

Cerca de quatro meses antes da publicação desta crônica, em artigo para o Avanti!, ${ }^{\mathrm{vi}}$ órgão oficial do Partido Socialista e do qual era colaborador, Gramsci assumira a defesa intransigente da escola, entendendo fazê-lo em nome da classe trabalhadora. O texto, intitulado “A escola é uma instituição séria?" (GRAMSCI, 1968, p. 101), era uma réplica à posição de um grupo de estudantes universitários, aos quais Gramsci se refere como "máfia escolar", que havia publicado difamações contra e escola e os professores em um "jornaleco" de Turim, compilado por eles próprios, chamado "La Campana".

Em seu texto, esses jovens conclamavam os operários que, segundo eles, não ligavam para a escola, a se solidarizar com a causa deles de realizar uma "obra santa", na luta "contra a pedanteria e o tédio da escola, contra o filisteísmo dos professores" (ibidem). Gramsci, porém, pergunta: "de fato, vão à escola os operários? Frequentam o ginásio, o liceu, a universidade, os operários? E por que o Avanti! se envolve com estas tarefas que os operários não assumem (consideram)?” (ibidem, p. 102). Diz ironicamente: “os operários devem se declarar solidários com os sacristãos que soam o 'La Campana', com a máfia escolar que pôs os professores em condições de não poder desenvolver sua atividade" (ibidem). Ao mesmo tempo, devem ser contrários ao Avanti,

[...] que defende a escola, que defende a seriedade do ensino, que gostaria que fosse restaurada a disciplina dos estudos a fim de que a instituição escolar renda algo à sociedade e não seja completamente desperdiçado o dinheiro, fatigosamente suado 


\section{http://periodicos.sbu.unicamp.br/ojs/index.php/etd DOSSIE}

dos trabalhadores, que o Estado dedica à instrução pública” (ibidem, 102. Grifos meus).

Vale a pena o Avanti!, um periódico de índole socialista, dedicar tanto espaço para responder aos jovens do "La Campana" em defesa da escola burguesa? A resposta de Gramsci é afirmativa e com ele concordam: "numerosos professores que nos agradeceram por nossa intervenção, que nos escreveram por estar indefesos contra a ação difamatória desta máfia que tenta submergir o seu prestígio e a sua autoridade sob um dilúvio de libelos vulgares" (ibidem, p. 103).

Mais adiante complementa:

O Avanti! interpreta a vontade da classe trabalhadora que quer uma escola alta $e$ séria, crisol de humanidade mais digna e civil e não querela trivial e criminosa dos pais de família e dos abjetos lucradores contra os professores, para obter com terror do ludibrio e da difamação diplomas e licenças não merecidas. (ibidem).

E visto que a administração pública da justiça não defende a escola e os professores dessa máfia: "Nós do Avanti! não temos hesitação em nos fazermos de Dom Quixote da seriedade da escola e da moralidade entre os estudantes, contra a preguiça e o ceticismo dos responsáveis" (ibidem).

Ora, por que Gramsci, por intermédio de um órgão de comunicação do partido comunista, defenderia a escola em nome da classe trabalhadora se, a seu ver, ela fosse uma instituição que atendesse apenas aos interesses da burguesia? Há algo, portanto, que a instituição escolar pode e deve render à sociedade e à classe trabalhadora: um ensino efetivo, que lhes possibilite a apropriação do saber que cabe a ela ensinar. Mas para tanto, é preciso que seja uma escola "alta e séria", que assegure o acesso dos trabalhadores a todos os níveis de ensino e que preserve as condições de trabalho dos professores e a disciplina dos estudos.

Observa-se, portanto, que a crítica gramsciana ao caráter classista da escola burguesa se dirige mais especificamente ao seu aspecto discriminatório, segregador, "oligárquico", como ele dirá posteriormente (GRAMSCI, 2006, C 12, p. 49), e que se manifesta fundamentalmente no fato de não proporcionar às camadas populares a apropriação do saber elaborado (as ciências, as humanidades e as artes), conservando-o como privilégio das elites. 


\section{ALGUNS CONCEITOS DOS "CADERNOS"}

Para avançar na compreensão da concepção gramsciana da educação, importa examinar alguns conceitos e posições que aparecem nos Cadernos do Cárcere.

\section{Estrutura e superestrutura}

Já no Caderno 4 Gramsci deixa claro que considera "a 'estrutura' como ponto de referência e de 'causação' dialética, não mecânica, das superestruturas” (GRAMSCI, 2002, C 4, p. 367).

No Caderno 10 esse tema é retomado, particularmente no parágrafo 41 , no qual Gramsci refuta a posição de Benedetto Croce segundo a qual a filosofia da práxis “'destaca' a estrutura da superestrutura", incorrendo em uma espécie de "dualismo teológico" que acaba por afirmar "um 'deus oculto-estrutura"”. Para Gramsci, essa interpretação de Croce "não é exata" nem "muito profunda", mas, ao contrário, "vazia e superficial", pois: "não é verdade que a filosofia da práxis 'destaque' a estrutura das superestruturas; ao contrário, ela concebe o desenvolvimento das mesmas como intimamente relacionado e necessariamente inter-relativo e recíproco" (GRAMSCI, 2001, C10, p. 369).

Além disso, na filosofia da práxis, nem mesmo como metáfora a estrutura poderia ser comparada a um "deus", isto é, a algo imóvel e absoluto, uma vez que ela é concebida como “a própria realidade em movimento" (GRAMSCI, 2001, C10, p. 369-370).

Ainda no parágrafo 41, Gramsci recorre a duas passagens de Marx para criticar a leitura mecanicista e determinista da relação entre estrutura e superestrutura. A primeira é a terceira tese sobre Feuerbach (MARX e ENGELS, 1991, p.12), a partir da qual ele indaga: "A afirmação das Teses sobre Feuerbach, de que 'o educador deve ser educado', não coloca uma relação necessária de reação ativa do homem sobe a estrutura, afirmando a unidade do processo do real?" (GRAMSCI, 2001, C10, p. 370).

Afasta-se, portanto, qualquer hipótese de determinismo e mecanicismo. Antes, estrutura e superestrutura formam uma totalidade dialética, um "bloco histórico" (ibidem).

A segunda citação diz respeito a um trecho do Prefácio à obra "Para a crítica da Economia Política" (MARX, 1978, p. 130), no qual Marx afirma que também pela superestrutura, isto é, das formas ideológicas, os homens tomam consciência do conflito entre as forças produtivas materiais e as relações de produção e o levam até o fim. Diz Gramsci: "Se os homens adquirem consciência de sua posição social e de seus objetivos no terreno das superestruturas, isto significa que entre estrutura e superestrutura existe um nexo necessário e vital" (GRAMSCI, 2001, C10, p. 389). 
Para exemplificar esse nexo e, também, para mostrar que a superestrutura não é mera ilusão, como pensava Croce, Gramsci recorre a algumas metáforas ou imagens, como a da relação entre o esqueleto e a pele:

\begin{abstract}
No corpo humano, certamente, não se pode dizer que a pele (bem como o tipo de beleza física historicamente dominante) seja mera ilusão, e que o esqueleto e a anatomia sejam a única realidade; todavia, por muito tempo, se disse algo similar. Valorizando a anatomia e a função de esqueleto, ninguém pretendeu afirmar que o homem (e muito menos a mulher) possa viver sem ela. Prosseguindo na metáfora, pode-se dizer que não é o esqueleto (em sentido estrito) que faz alguém se enamorar por uma mulher, mas compreende-se quanto o esqueleto contribui para a graça dos movimentos, etc. (GRAMSCI, 2001, C10, p. 389-390).
\end{abstract}

O fato de a relação entre estrutura e superestrutura não ser mecânica, mas dialética e de ação recíproca, e de a superestrutura (instância na qual se encontra a escola) ser também o âmbito no qual os homens tomam consciência do conflito entre as forças produtivas materiais e as relações de produção e o levam até o fim, permite concluir que, para Gramsci, a escola não é apenas instrumento de reprodução da ordem vigente. Mesmo a escola burguesa, com todas as limitações inerentes a seu caráter oligárquico, atende, em alguma medida, também aos interesses dos trabalhadores, desde que, porém, seja, também para eles, uma escola séria.

\title{
Racional $^{\text {vii }}$
}

No Caderno 14 Gramsci discute os conceitos de inovador e racional, estabelecendo a respeito desses termos uma distinção fundamental entre a perspectiva romântica e a perspectiva da filosofia da práxis.

Do ponto de vista romântico, diz ele, inovador é "quem quer destruir todo o existente sem preocupar-se com o que acontecerá depois". Essa noção se baseia na crença metafísica de que "toda destruição é criação" e de que "só se destrói aquilo que se substitui recriando". Baseia-se também em uma visão conspiratória, persecutória, segundo a qual "tudo o que existe é uma 'armadilha dos fortes contra os fracos, dos espertos contra os pobres de espírito", tomando-se as palavras literalmente, "ao pé da letra", "de modo iluminista" (Gramsci, 2011, C 14, p. 257).

Gramsci contrapõe a essa visão romântica e "iluminista"” a perspectiva da filosofia da práxis, segundo a qual "toda coisa que existe é 'racional', isto é, teve ou tem uma função útil" (ibidem) na medida em que responde a determinadas condições históricas.

O fato de que algo exista em conformidade com os interesses (o modo de viver, pensar, agir, sentir, etc.) da classe dirigente, não significa que se tornará automaticamente " "irracional'", tão logo essa classe deixe de ser dirigente. Nesses casos, é preciso investigar se persiste alguma racionalidade, isto é, se ainda se fazem presentes as condições em que se baseava a racionalidade original. Somente quando essas condições desaparecem é que esse algo se torna "irracional", não tendo mais razão de existir. Deve-se, portanto, reconhecer e levar 
em conta a "'historicidade" dos modos de viver e de agir, a fim de evitar a perspectiva odiosa, persecutória, idealista.

Em suma, o que antes foi " "racional"” só deve ser combatido na medida em que não mais o for, isto é, quando não mais estiver em conformidade com os fins a que se destina e com as condições históricas que lhe conferia racionalidade, passando a "se arrastar pela viscosidade do hábito" (ibidem, p. 258). Além disso, o fato de certo modo de viver, pensar e agir se tornar “"irracional" "em um determinado ambiente não significa que se tenha tornado irracional em todos os ambientes e para todas as pessoas e que, por isso, seria estupidez ou perversidade preservá-lo. Por outro lado, o fato de um modo de viver, pensar e agir se tornar irracional em algum lugar é muito importante, pois permite substituí-lo, nesse lugar, por outro, de caráter historicista, o que ajudará a quebrar a viscosidade do costume e facilitará a introdução de mudanças mais amplas quando as condições históricas permitirem (ibidem).

Além disso, "que um modo de viver, de operar, de pensar se tenha introduzido em toda a sociedade porque próprio da classe dirigente não significa por si só que seja irracional e deva ser rejeitado" (ibidem). Em tudo há sempre dois aspectos: um "racional", isto é, de conformidade com um fim, e outro que é "de "moda"'. Os exemplos apresentados são bastante esclarecedores:

Usar sapatos é racional, mas o estilo determinado de sapato se deverá à moda. Usar colarinho é racional, porque permite troar com frequência aquela parte do vestuário, a 'camisa', que mais facilmente se suja, mas o estilo do colarinho dependerá da moda, etc. (ibidem, p. 258-259).

Não se podem confundir "a utilidade permanente (enquanto o for) com a moda". Fazer essa confusão é "um modo de pensar típico de quem usa antolhos". Em síntese, é preciso distinguir o "o permanente, o útil, o racional, o conforme ao fim (enquanto subsistir o fim) do acidental, do esnobe, da macaqueação" (ibidem, p. 259). Gramsci conclui com um exemplo pertinente ao tema escolar:

[...] ninguém (a menos que seja louco) defenderá que não mais se ensine a ler e a escrever, porque ler e escrever certamente foram introduzidos pela classe dirigente, porque a escrita serve para difundir certa literatura ou para as cartas de chantagem e os relatórios dos informantes. (Ibidem, p. 259).

A noção de "racional", portanto, parece ser uma importante chave interpretativa para ajudar na compreensão da concepção gramsciana da educação. Com efeito, a escola, como instituição burguesa, representa o modo de viver, agir e pensar dessa classe e, portanto, reflete e reproduz sua visão de mundo. Além disso, como instância da sociedade civil, ela é diretamente (mas não absolutamente) controlada por essa classe, justamente para que atenda majoritariamente a seus interesses. Mas isso não significa que a escola seja, por si só, irracional e que deva ser rejeitada como um todo. Afinal, permanecem as condições históricas que lhe conferem racionalidade, que a tornam útil e necessária, inclusive (ou sobretudo) para a classe trabalhadora - embora, particularmente para ela, certos modismos pedagógicos cheguem 
mesmo a comprometer a consecução dos seus fins. De fato, só pelo efeito do uso de antolhos ou por completa insanidade se poderia deixar de reconhecer a utilidade permanente da escola nas condições históricas atuais.

\section{Estado integral}

No parágrafo 47 do Caderno 1 (GRAMSCI, 2011, p. 119), intitulado Hegel e o associacionismo, Gramsci já dava indicações de sua concepção do Estado, evidenciando: 1) que o entende mais amplamente que na doutrina marxista tradicional, incluindo neste conceito, além das instâncias da "sociedade política", também as da "sociedade civil"; 2) que o Estado exerce, justamente por meio da sociedade civil, a função de educador do consenso.

Inicialmente, porém, convém elucidar as noções de sociedade civil e sociedade política. No Caderno 12 esclarece que se trata de "dois grandes 'planos' superestruturais”, cujos papéis são assim determinados: a sociedade civil compreende "o conjunto de organismos designados vulgarmente como "privados" e cumpre a "função de 'hegemonia' que o grupo dominante exerce em toda a sociedade"; a sociedade política, por sua vez, compreende o Estado propriamente dito e exerce o papel de “'domínio direto' ou de comando, que se expressa no Estado e no governo “jurídico”” (GRAMSCI, 2006, C12, p. 20-21).

Os principais responsáveis pelas "funções subalternas da hegemonia social e do governo político" são os intelectuais, que atuam no âmbito da sociedade civil e da sociedade política como funcionários nomeados pelo grupo dominante (como seus "prepostos", para usar o termo de Gramsci). Essas funções se resumem, basicamente, em duas:

1) a função do "consenso "espontâneo"” que a classe dominante precisa obter das massas populares em relação à orientação que ela imprime à vida social, consenso este que está lastreado no prestígio e na confiança de que goza essa classe em razão de sua posição no mundo da produção;

2) a função do "aparelho de coerção estatal”, responsável por garantir "“legalmente" a disciplina dos segmentos que "não 'consentem', nem ativa nem passivamente" (ibidem, p. 21). O aparelho de coerção, contudo, é organizado visando a toda a sociedade, como forma de precaução para os momentos de crise no comando ou na direção dessa sociedade, nos quais o consenso espontâneo desaparece.

Assim, em Gramsci, a noção de Estado inclui a "sociedade civil" e a "sociedade política". A relação do Estado com a sociedade civil se expressa hegelianamente viii como uma "trama "privada"” (GRAMSCI, 2011, C1, p. 119). Em outros termos, Estado, para ele, implica equilíbrio entre sociedade política (força, coerção, intervenção estatal) e sociedade civil (hegemonia, consenso, direção cultural). No Caderno 6 reitera essa concepção, afirmado que "na noção geral de Estado entram elementos que devem ser remetidos à noção de sociedade civil (no sentido, seria possível dizer, de que Estado = sociedade política + sociedade civil, isto 
é, hegemonia couraçada de coerção" (GRAMSCI 2011, C 6, p. 244). Mais adiante, reforça: “por Estado deve-se entender, além do aparelho de governo, também o aparelho 'privado' de hegemonia ou sociedade civil” (ibidem, p. 254-255).

Na mesma época em que escrevia essas notas, em carta à cunhada Tatiana, de 7 de setembro de 1931, Gramsci menciona certas implicações do estudo que fizera sobre a questão dos intelectuais para o conceito de Estado, esclarecendo ainda mais as ideias acima apresentadas. Ele diz:

Este estudo também leva a certas determinações do conceito de Estado, que, habitualmente, é entendido como sociedade política (ou ditadura, ou aparelho coercivo, para moldar a massa popular segundo o tipo de produção e a economia de um dado momento), e não como um equilíbrio da sociedade política com a sociedade civil (ou hegemonia de um grupo social sobre toda a sociedade nacional, exercida através das organizações ditas privadas, como a igreja, os sindicatos, as escolas, etc.), e é especialmente na sociedade civil que operam os intelectuais (Ben. Croce, por exemplo, é uma espécie de papa laico e é um instrumento muito eficaz de hegemonia, ainda que vez por outra possa divergir deste ou daquele governo, etc.) (GRAMSCI, 2005, v. 2, p. 84).

Ainda a respeito da sociedade civil, Liguori (2007, p. 49) salienta que ela "não é homogênea, é, antes, um dos principais teatros da luta entre as classes em que se manifestam intensas contradições sociais". E embora a sociedade civil, como momento da superestrutura, seja determinada em última instância pelas relações de força entre as classes, isto é, pela luta política efetiva, "não se pode subestimar o papel da batalha das ideias na definição das relações de força" (ibidem, p. 54). Com efeito, na perspectiva gramsciana, diz o autor, "a sociedade civil é uma arena privilegiada da luta de classes, uma esfera do ser social em que se dá uma intensa luta pela hegemonia" (ibidem).

É também por meio da sociedade civil que o Estado exerce a função de educador. Afinal, o governo precisa ter o consenso dos governados. Mas este consenso deve ser "organizado" e não "genérico e vago", como ocorre, por exemplo, em época eleitoral. Por isso, o Estado precisa também "educar" esse consenso. Diz Gramsci: "O Estado tem e pede o consenso, mas também 'educa' este consenso através das associações políticas e sindicais, que, porém, são organismos privados, deixados à iniciativa privada da classe dirigente" (Gramsci, 2011, C1, p. 119). Esses organismos privados que constituem a sociedade civil incluem também as instituições educativas.

Essa noção do Estado educador reaparece no Caderno 8, acrescida de uma dimensão ética. Diz Gramsci: 
[...] todo Estado é ético na medida em que uma de suas funções mais importantes é elevar a grande massa da população a um determinado nível cultural e moral, nível (ou tipo) que corresponde à necessidade de desenvolvimento das forças produtivas e, portanto, aos interesses das classes dominantes. A escola como função educativa positiva e os tribunais como função educativa repressiva e negativa são as atividades estatais mais importantes nesse sentido; mas, na realidade, para tal fim tende uma multiplicidade de outras iniciativas e atividades ditas privadas, que formam o aparelho da hegemonia política e cultural das classes dominantes. (GRAMSCI, 2011, C 8, p. 284. Grifos meus).

A escola, portanto, como elemento da superestrutura e da sociedade civil, atua como um dos aparelhos de hegemonia do Estado, do qual este se vale para educar o consenso em conformidade com os interesses da classe que o controla. Os agentes dessa educação são os intelectuais (os "prepostos" da classe dominante) que agem no campo da sociedade civil, ou seja, no caso da escola, os professores.

Evidencia-se, assim, a função de hegemonia exercida por esta instituição. Mas já vimos que, para Gramsci, a relação entre estrutura e superestrutura não é mecânica e absoluta, mas dialética e de determinação recíproca. Isso significa que, mesmo como aparelho de hegemonia, a escola não é puro reflexo da estrutura social. Além disso, se o Estado precisa também da coerção exercida pela sociedade civil para educar o consenso é porque a função de hegemonia não é totalmente garantida, sobretudo se se considera que é no âmbito da sociedade civil que os "os homens adquirem consciência de sua posição social e de seus objetivos" (Gramsci, 2001, C10, p. 389). Ora, se essa tomada de consciência se dá no interior da superestrutura, nas diversas instituições da sociedade civil, isso significa que elas são também espaço de luta cultural, política, ideológica, enfim, de luta por hegemonia, travada por intelectuais (professores, no caso da escola) comprometidos mais ou menos conscientemente com as classes fundamentais da sociedade.

\section{Guerra de movimento e guerra de posição}

A vitória da revolução socialista de 1917 gerou no movimento operário internacional um sentimento de que a ruptura com o capitalismo estava em vias de acontecer em escala mundial. O próprio Gramsci, no período das lutas operárias em Turim, não escondia o entusiasmo por aquele momento particular, como se observa em suas palavras no artigo "Um esfacelamento e uma gênese", publicado no L'Ordine Nuovo de 1 de maio de 1919: "Na classe dos operários e camponeses repousa a juventude renascente da civilização humana. (...) Uma sociedade, a capitalista, está se esfacelando; uma revolução, a comunista, está em marcha batida" (apud DIAS, 2000, p. 120).

Não tardou, porém, para que a realidade contrariasse as expectativas. As derrotas do movimento operário, particularmente da experiência dos Conselhos de Fábrica, em Turim, em 1920, acompanhadas do advento do fascismo e do nazismo, entre outros fatores, mostraram que, no Ocidente, a revolução proletária demandaria uma luta diversa, mais árdua e demorada 
que aquela acontecida na Rússia. Em carta a Togliatti e a outros companheiros do Partido Comunista Italiano, de 9 de fevereiro de 1924, Gramsci demonstra perceber a necessidade de uma nova estratégia revolucionária:

\begin{abstract}
A determinação que na Rússia era direta e lançava as massas às ruas para o assalto revolucionário, complica-se na Europa Central e Ocidental em função de todas estas superestruturas políticas, criadas pelo maior desenvolvimento do capitalismo; tornase mais lenta e mais prudente a ação das massas e, portanto, requer do partido revolucionário toda uma estratégia e uma tática bem mais complexas e de longo alcance do que aquelas que foram necessárias aos bolcheviques no período entre março e novembro de 1917. (GRAMSCI, 2004, p.183-184).
\end{abstract}

Prepara-se, já aqui, o terreno para as noções de "guerra de movimento" e "guerra de posição" que viriam a ser desenvolvidas nos Cadernos. O tema aparece em várias outras notas, mas talvez seja no Caderno 7 que elas são mais claramente explicitadas. Sucintamente, a "guerra de movimento" é aquela que visa efetivamente à tomada do poder de Estado, tal como ocorreu, por exemplo, com a revolução de 1917. No Oriente isso foi possível, segundo Gramsci, porque a sociedade civil era "primitiva e gelatinosa". No Ocidente, porém, a sociedade civil é muito mais desenvolvida e bem articulada ao Estado, atuando como uma "robusta cadeia de fortalezas e casamatas" em sua defesa. Em sociedades desse tipo só è possível a "guerra de posição", que consiste em lutar no campo da sociedade civil visando a construir uma nova hegemonia. Nas palavras de Gramsci:

"Parece-me que Ilitch [Lênin] havia compreendido a necessidade de uma mudança da guerra manobrada, aplicada vitoriosamente no Oriente em 1917, para a guerra de posição, que era a única possível no Ocidente, onde, como observa Krasnov, num breve espaço de tempo os exércitos podiam acumular quantidades enormes de munição, onde os quadros sociais eram por si sós ainda capazes de se tornarem trincheiras municiadíssimas" (Gramsci, 2002, C7, p. 262). ${ }^{\text {ix }}$

No Caderno 10 as noções de "Guerra de posição" e "guerra de movimento" reaparecem ligadas ao conceito de "revolução passiva". Não são propriamente desenvolvidos, mas são exemplificadas, o que pode ajudar no seu esclarecimento. A Revolução Francesa seria uma guerra de movimento, seguida de uma guerra de posição; na época de Gramsci, a guerra de movimento foi a I Guerra Mundial (1917-1921), seguida de uma guerra de posição, cujo representante prático e ideológico (na Europa) foi o fascismo (Gramsci, 2001, C 10, p. 299$300)$.

Em suma, pode-se dizer de modo simplificado que a guerra de posição é a luta por hegemonia no interior da sociedade civil, que, como vimos pelas palavras de Liguori, é uma "arena privilegiada da luta de classes", não se podendo, portanto, subestimar a importância desse campo de batalha no processo de transformação social. 


\section{CONSIDERAÇÕES FINAIS}

Evidentemente, os textos aqui utilizados não esgotam as fontes bibliográficas cujo exame se faz necessário para o delineamento mais amplo e preciso da concepção gramsciana da escola e do caráter classista dela. Há, sem dúvida, diversas outras referências a serem examinadas visando a esse objetivo. Basta lembrar, por exemplo, o importantíssimo Caderno 12, no qual Gramsci apresenta mais sistematicamente temas como o dos intelectuais e o da escola unitária. Isso para não mencionar numerosas notas espalhadas por diversos Cadernos, além de cartas e muitos outros artigos jornalísticos que, mais ou menos diretamente, tratam de temas pedagógicos.

Dados, porém, os limites deste artigo, decidi pôr em relevo, neste momento, os textos de 1919 supracitados, a fim de extrair sua contribuição, a meu ver, relevante, para o tema em pauta e, ao mesmo tempo, ampliar as fontes que costumeiramente alimentam o debate em torno das ideias pedagógicas de Gramsci. Cumpre, porém, prosseguir com a pesquisa, aprofundando o estudo dessas fontes.

Acredito que as considerações acima permitem concluir que, para Gramsci, a escola, como elemento da superestrutura e da sociedade civil é, de fato, aparelho de hegemonia da classe dominante. Mas não apenas isto. Como terreno de luta cultural, isto é, campo de batalha por hegemonia, travada na forma de guerra de posição, a escola é, também, contraditoriamente, instrumento de luta pela construção de uma nova hegemonia, luta essa que é cotidianamente travada, mais ou menos conscientemente, pelos intelectuais que nela têm seu campo específico de atuação: os professores.

Os textos aqui analisados podem ajudar a compreender o significado concreto de tal luta cultural: trata-se, basicamente, de fazer com que a escola ensine também aos filhos dos trabalhadores aquilo que ela não deixa de ensinar aos filhos das elites: a arte, a ciência, a filosofia, enfim, "um milênio de trabalho de pensamento", elementos culturais de "valor eterno, que não podem, que não devem perecer", a fim de que também essa classe desenvolva um "senso novo de dignidade e de liberdade". Nisto consiste, em grande parte, a força políticotransformadora dessa instituição, seu potencial contra hegemônico. Para tanto, porém, é preciso restaurar a "seriedade do ensino", a "disciplina dos estudos", dando de fato um caráter público aos investimentos do Estado em educação. Ora, encontram-se aqui, embrionariamente, aspectos essenciais da "escola unitária", que Gramsci desenvolverá no Caderno 12, e que precisa ser também uma escola "desinteressada" e de cultura humanística para capacitar as camadas subalternas a se tornarem governantes (GRAMSCI, 2006, C 12, p. 50).

Essa parece ser uma das formas mais efetivas de articulação da escola com os interesses dessas camadas e sua contribuição específica para a superação da sociedade de classes: favorecendo aos trabalhadores a apropriação de um conjunto de saberes e habilidades necessários à luta deles por hegemonia. 
É por essa escola que vale a pena lutar, mesmo que ainda se trate da escola burguesa que, no entanto, permanece racional. Dessa perspectiva, seria, portanto, um equívoco subestimar a importância dessa instituição como campo de batalha da guerra de posição em favor de outra hegemonia e como instrumento - por mediação - de transformação social.

A esse respeito, vale lembrar também a observação de Gramsci de que a escola, assim como a Igreja, é uma das maiores organizações culturais por causa do grande número de pessoas que atinge, razão pela qual pode ser um poderoso veículo de difusão das novas concepções do mundo. Isso, porém, não acontece, ou pelo menos não com a abrangência que seria desejável, pelo fato de ainda haver um grande distanciamento entre os intelectuais e as massas, sobretudo os professores, justamente aqueles que estão entre os "mais próximos à periferia nacional" (Gramsci, 2001, C 11, v. 1, p. 112). Cumpre, portanto, eliminar essa distância e fazer do trabalho pedagógico uma ocasião de autêntico contato entre os intelectuais - professores - e os "simples" - estudantes -, de modo a favorecer uma elevação cultural de massa. E é ela, a escola pública, o local privilegiado para este contato. Afinal, onde mais, em que outra esfera da sociedade civil, os intelectuais comprometidos com as camadas subalternas encontrarão condições tão favoráveis para se engajarem em um trabalho de "elevação cultural de massa"? Como lembra Giorgio Baratta (2011, p. 44):

Há um nível de vida, um âmbito da sociedade civil, em que o encontro entre intelectuais e simples (a começar pelas crianças) é a realidade cotidiana: a escola. É na escola que tem sua raiz aquilo que chamamos de "modo de produção cultural", com todas as suas contradições, potencialidades e perspectivas, tanto positivas como negativas.

Mutatis mutantis, pode-se até dizer que as mesmas razões pelas quais Althusser (1989) considerou a escola como "aparelho ideológico dominante" nas formações sociais capitalistas fazem dela, também, um espaço privilegiado para a luta contra a hegemonia burguesa. ${ }^{\mathrm{x}}$

Com efeito, a despeito da notória precariedade em que vem sendo mantida boa parte das escolas públicas, é nelas que se reúnem obrigatória e diariamente, cinco dias por semana, ao longo de vários anos, centenas de milhares de crianças e jovens (quase a totalidade da população na faixa etária correspondente aos níveis iniciais), acomodadas em um espaço físico especificamente planejado para atividades pedagógicas, à espera de que algo relevante lhes seja ensinado. Não se trata de abstrair os obstáculos de toda ordem cotidianamente enfrentados por educadores, estudantes e pais, nem de subestimar a vultuosidade e a aridez da tarefa política e pedagógica que o enfrentamento desses obstáculos representa, mas de reconhecer a escola como uma frente de batalha estratégica fundamental e da qual não pode abdicar o intelectual comprometido com as camadas subalternas.

Assim, a posição gramsciana a respeito da relação educação e sociedade permite superar tanto do idealismo característico da perspectiva liberal, quanto do determinismo e o imobilismo de algumas teorias reprodutivistas, ajudando a identificar as reais possibilidades de intervenção social por meio da ação educativa escolar com vistas à construção de uma nova hegemonia. 


\section{REFERÊNCIAS}

ALTHUSSER, Louis. Aparelhos ideológicos de Estado. Rio de Janeiro: Graal, 1989.

BARATTA, Giorgio. Escola, filosofia e cidadania no pensamento de Gramsci: exercícios de leitura. Pro-Posições, Campinas, SP, v. 21, n. 1 (61), p. 31-49. jan./abr. 2010. Disponível em: $<$ http://goo.gl/KrDbNf $>$. Acesso em: 14 jul. 2015. ISSN 1980-6248.

COSTA, Ricardo da Gama Rosa. Marxismo e revolução: da "Estratégia de Derrocada" à "Guerra de Posições". História \& luta de classes, Curitiba, PR, n. 5, p. 15-22. abr. 2008. Disponível em: < http://goo.gl/icZJwg>. Acesso em: 14 jul. 2015.

CUNHA, Luiz Antônio. Educação e desenvolvimento social no Brasil. Rio de Janeiro: Livraria Francisco Alves, 1979.

DIAS, Edmundo Fernan. Gramsci em Turim: a construção do conceito de hegemonia. São Paulo: Xamã, 2000.

GRAMSCI, Antonio. Caderno 1 (1929-1930). In: Cadernos do cárcere. Maquiavel. Notas sobre o Estado e a política. Tradução de Luiz Sérgio Henriques, Marco Aurélio Nogueira e Carlos Nelson Coutinho. 4. ed., Rio de Janeiro: Civilização Brasileira, v. 3, 2011, p. 119-125.

GRAMSCI, Antonio. Caderno 4 (1930-1932). In: Cadernos do cárcere. O Risorgimento. Notas sobre a história da Itália. Tradução de Luis Sérgio Henriques. Rio de Janeiro: Civilização Brasileira, v. 5, 2002, p. 209-210.

GRAMSCI, Antonio. Caderno 6 (1930-1932). In: Cadernos do cárcere. Maquiavel. Notas sobre o Estado e a política. Tradução de Luiz Sérgio Henriques, Marco Aurélio Nogueira e Carlos Nelson Coutinho. $4^{\mathrm{a}}$ edição, Rio de Janeiro: Civilização Brasileira, v. 3, 2011, p. 223 259.

GRAMSCI, Antonio. Caderno 7 (1930-1932). In: Cadernos do cárcere. Literatura. Folclore. Gramática. Apêndices: Variantes e índices. Tradução de Carlos Nelson Coutinho e Luiz Sérgio Henriques. Rio de Janeiro: Civilização Brasileira, v. 6, 2002, p. 368-374.

GRAMSCI, Antonio. Caderno 8 (1931-1932). In: Cadernos do cárcere. Maquiavel. Notas sobre o Estado e a política. Tradução de Luiz Sérgio Henriques, Marco Aurélio Nogueira e Carlos Nelson Coutinho. $4^{\mathrm{a}}$ edição, Rio de Janeiro: Civilização Brasileira, v. 3, 2011, p. 271289.

GRAMSCI, Antonio. Caderno 10 (1932-1935) - A filosofia de Benedetto Croce. In: Cadernos do cárcere. Introdução ao Estudo da Filosofia. Edição de Carlos Nelson. Coedição de Marco Aurélio Nogueira e Luiz Sérgio Henriques. Tradução de Carlos Nelson Coutinho. Rio de Janeiro, Civilização Brasileira, 2001, v. 1, p. 275-430.

GRAMSCI, Antonio. Caderno 11 (1932-1933). Introdução ao Estudo da Filosofia. In: Cadernos do cárcere. Introdução ao Estudo da Filosofia. A filosofia de Benedetto Croce. Edição de Carlos Nelson Coutinho. Coedição de Marco Aurélio Nogueira e Luiz Sérgio 
Henriques. Tradução de Carlos Nelson Coutinho. Rio de Janeiro, Civilização Brasileira, v. 1, 2001, p. 81-226.

GRAMSCI, Antonio. Caderno 12 (1932). Apontamentos e notas para um grupo de ensaios sobre a história dos intelectuais. In: Cadernos do cárcere. Os intelectuais. O princípio educativo. Jornalismo. Tradução de Carlos Nelson Coutinho. Rio de Janeiro: Civilização Brasileira, v. 2, 2006, p. 13-53.

GRAMSCI, Antonio. Caderno 14 (1932-1935). In: Cadernos do cárcere. Maquiavel. Notas sobre o Estado e a política. Tradução de Luiz Sérgio Henriques, Marco Aurélio Nogueira e Carlos Nelson Coutinho. $4^{\text {a }}$ edição, Rio de Janeiro: Civilização Brasileira, v. 3, 2011, p. 297322.

GRAMSCI, Antonio. Caderno 19 (1934-1935) [Risorgimento italiano]. In: Cadernos do cárcere. O Risorgimento. Notas sobre a história da Itália. Tradução de Luis Sérgio Henriques. Rio de Janeiro: Civilização Brasileira, v. 5, 2002, p. 11-128.

GRAMSCI, Antonio. Cartas do cárcere (1931-1937). Tradução de Luiz Sérgio Henriques. Organizadores: Carlos Nelson Coutinho e Luiz Sérgio Henriques. Rio de Janeiro: Civilização Brasileira, v. 2, 2005.

GRAMSCI, Antonio. Escritos políticos. Tradução de Carlos Nelson Coutinho. v. 2. 19211926. Rio de Janeiro: Civilização Brasileira, 2004.

GRAMSCI, Antonio. L'ordine Nuovo: 1919-1920. Torino: Giulio Einaudi Editore, 1955.

GRAMSCI, Antonio. Scritti 1915-1921. Nuovi contributi. A cura di Sergio Caprioglio. Quaderno di Il Corpo. Milão, 1968.

LIGUORI, Guido. Roteiros para Gramsci. Rio de Janeiro: Editora UFRJ, 2007.

MANACORDA, Mario Alighiero. O princípio educativo em Gramsci. Tradução de William Lagos e Tomaz Tadeu da Silva. Porto Alegre: Artes Médicas, 1990.

MANACORDA, Mario Alighiero. O princípio educativo em Gramsci. Tradução de William Lagos. Campinas: Editora Alínea, 2008.

MARX, Karl; ENGELS, Friedrich. A ideologia alemã (Feuerbach). São Paulo: Hucitec,1991.

MANN, Horace. A educação dos homens livres. Tradução de Jacy Monteiro. São Paulo: IBRASA, 1963.

SAVIANI, Dermeval. Escola e democracia. 41. ed. Campinas: Autores Associados, 2009.

SNYDERS, Georges. Escola, classe e luta de classes. Lisboa: Moraes, 1977. 


\footnotetext{
${ }^{\text {i }}$ Essa maneira de discriminar as teorias pedagógicas aproxima-se da posição de Dermeval Saviani (2009, p. 3).

ii Cf. também: CUNHA, 1979, p. 44

iii A essas teorias Saviani (2009, p. 5) denominou "crítico-reprodutivistas".

iv L'Ordine Nuovo [A Nova Ordem], cujo subtítulo era "Resenha Semanal de Cultura Socialista", foi um periódico fundado por Gramsci e seus companheiros de militância Angelo Tasca, Palmiro Togliatti e Umberto Terracini, em 1919, em Turim, com o objetivo de discutir livremente temas como imperialismo, Estado, revolução, entre outros de interesse do movimento operário. O primeiro número, publicado em $1^{\circ}$ de maio, trazia a sugestiva palavra de ordem: "Instruí-vos, porque precisamos da vossa inteligência. Agitai-vos, porque precisamos do vosso entusiasmo. Organizai-vos, porque carecemos de todo a vossa força" (cf.: COUTINHO, 2001, p. 54). Observa-se, já aqui, a importância política atribuída por Gramsci à instrução da classe trabalhadora. Algumas edições digitalizadas do semanário podem ser encontradas nos endereços: http://www.resistenze.org/sito/ma/di/ds/mddsba18-008134.htm e http://www.centrogramsci.it/riviste/riviste.htm [acessados em 8/07/2015].

${ }^{v}$ Cf.: Crônica IX. L’Ordine Nuovo, 23 de agosto de 1919, ano I, p. 15. In: GRAMSCI, 1955, p. 118-120. A tradução é minha.

${ }^{v i}$ Cf.: Avanti! Edizione piemontese. Ano XXIII, n. 93, 3 abril de 1919. In: GRAMSCI, 1968 p. 101-103.

Tradução minha.

vii Essa noção de "racional" parece assemelhar-se à de "clássico", empregada por Gramsci, no Caderno 12, em contraposição a "romântico". Referindo-se à crítica da escola ativa - entenda-se escola nova - à escola tradicional, ele diz: "Ainda se está na fase romântica da escola ativa, na qual os elementos da luta contra a escola mecânica e jesuítica se dilataram morbidamente por razões de contraste e polêmica: é necessário entrar na fase 'clássica', racional, encontrando nos fins a atingir a fonte natural para elaborar os métodos e as formas" (GRAMSCI, 2006, p. 39). Cumpre, porém, analisar mais detidamente essa possível semelhança.

viii A noção gramsciana do Estado inspira-se nas formulações de Hegel (cf. Gramsci, 2011, v. 3. p. 383-384, nota 2).

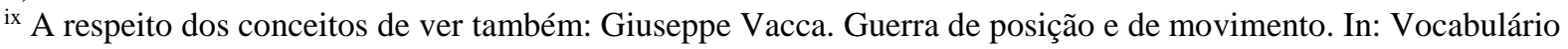
gramsciano. Disponível em:

http://www.acessa.com/gramsci/texto_visualizar.php?mostrar_vocabulario=mostra\&id=643.

${ }^{x}$ Diz Althusser: "nenhum aparelho ideológico do Estado dispõe durante tantos anos da audiência obrigatória (e por menos que isso signifique, gratuita...), 5 a 6 dias num total de 7, numa média de 8 horas por dia, da totalidade das crianças da formação social capitalista" (1989, p. 80).
}

\section{Agradecimentos}

Agradeço à FAPESP pela concessão da bolsa Pesquisa no Exterior, que permitiu a realização do estágio de pós-doutoramento do qual resultou este artigo. Agradeço também, de modo especial, ao Prof. Dr. Angelo D’Orsi, da Università degli Studi di Torino, pelo acolhimento e pela cuidadosa supervisão do trabalho de pesquisa.

\section{Como citar este documento:}

SILVEIRA, Rene Trentin. Escola e classe social de uma perspectiva gramsciana: a sala de aula, o intelectual e os simples. ETD - Educação Temática Digital, Campinas, SP, v. 17, n. 3, nov. 2015. ISSN 1676-2592. Disponível em: <http://periodicos.sbu.unicamp.br/ojs/index.php/etd/article/view/8638307>. Acesso em: 16 dez. 2015. 